\title{
AC 2008-1096: DESIGN AND IMPLEMENTATION OF A HYDROGEN FUEL CELL DATA ACQUISITION AND MONITORING SCHEME FOR EDUCATIONAL INSTITUTIONS
}

Recayi "Reg" Pecen, University of Northern Iowa

Faruk Yildiz, University of Northern Iowa

Kenan Baltaci, University of Northern Iowa 


\title{
Design and Implementation of a Hydrogen Fuel Cell Data Acquisition and Monitoring Scheme for Educational Institutions
}

\begin{abstract}
One of the challenges of the fuel cell power systems is proper monitoring, instrumentation and data acquisition of system parameters such as fuel flow into the system, AC and DC voltage values, load current, humidity, DC and AC power, pressure, temperature, fuel utilization, overall system efficiency, noise, etc. Fuel cell test systems must precisely monitor and control these measurements in real-time. It is necessary to have an instrumentation system which is able to monitor and control fuel cell operation under varying conditions. Therefore, a typical fuel cell test system requires high-resolution, isolation, and waveform acquisition capability. This paper describes design and implementation of a hydrogen fuel cell data acquisition and monitoring scheme for a BS degree offering engineering technology institution. The objective of this applied research project is to design and implement a high-resolution data acquisition and interface module for a $500 \mathrm{~W}$ Hydrogen fuel cell power station using LabView ${ }^{\mathrm{TM}}$ PDS v8.20 software and field point based data acquisition modules. The developed data acquisition system is used as an educational tool in undergraduate and graduate instrumentation and data acquisition classes.
\end{abstract}

\section{Introduction}

The conventional approach to hydrogen fuel cell system design has been defining the system design point requirements. That is, for a particular energy system the design operating point requirements, such as, hydrogen fuel or power providing capacity for energy based application system, and performance issues, such as, effectiveness or performance coefficient would be specified. The system designer would then decide on selecting hardware components, instrumentation and data acquisition software that would work together in a system to accomplish the required task and meet performance requirements at the design operating point. In this data acquisition and monitoring scheme, the decision to select particular components for the overall system was considered with high importance to avoid system failures. Relevant and competent system modules will be more efficient and save sufficient money over the life of the system to avoid the additional expense and time.

The teaching of the design and implementation of energy systems and the use of data acquisition and monitoring scheme allow the students to consider alternative equipment selections and programming interfaces. The utilization of data acquisition system allows the students or system designers not only to complete a workable system, but also, to obtain a design and implementation system that is optimized based upon a specified design criterion. Furthermore, with the improvement of computer hardware, data acquisition devices and easy to use software, the student can now accomplish much more complex systems. These improvements can take away spending an inconsistent amount of lecture time and effort on the calculations involved in the solution of systems of equations crucial to create energy systems. Many appropriate data acquisition and instrumentation software packages are available. For this work NI LabView ${ }^{\mathrm{TM}}$ virtual instrument to acquire experimental data was found to be a convenient and useful tool. The NI LabView ${ }^{\mathrm{TM}}$ data logging and supervisory control module from National Instruments meet the needs of fuel cell researchers with its built-in high-channel-count data acquisition, data logging, 
interface, and security capabilities. Fuel cell test systems may require hundreds of data acquisition sensors and controls for temperature, humidity, atmospheric pressure, power level, and other parameters. A typical test may include a parameter such as temperature to a certain point, holding it steady, and graphing the resulting voltage and current across the fuel cell. The NI LabView ${ }^{\mathrm{TM}}$ data logging and supervisory control module includes an extensive historical database in which all measurement and test data acquired can be saved for later review and the user can load in test data and perform interactive offline analysis and report generation. These NI LabView $^{\mathrm{TM}}$ features allow the students to concentrate on the engineering involved in the project practically without being confused by the details and characteristics of the different measurements devices with strict requirements and long data sheets. Electrical and Information Engineering Technology students at undergraduate and graduate levels at the University of Northern Iowa established a Hydrogen Fuel-Cell project using 500W Hydrogen Fuel-Cell Power station originally donated by Alliant Energy and owned by Iowa Renewable Association to design and develop a data acquisition and instrumentation system using NI LabView ${ }^{\mathrm{TM}}$ software and field point data acquisition tools. The latest version of the LabView $^{\mathrm{TM}} \mathrm{v} 8.20$ is purchased by a grant provided by the Dean of College.

\section{Hydrogen Fuel Cell Technology}

The depleting fossil fuel resources and increasing climate change and global warming impacts are leading to the research and development of alternative energy technologies. Hydrogen Fuel cell systems have a high efficiency and use easily available hydrocarbons like methane thus alleviating the fuel shortage. Since the by-product is water, vapor and heat, they have a very low

environmental impact ${ }^{1}$. The hydrogen fuel cell system consists of several subsystems and a lot of effort in diverse areas is required to make it a popular choice for power generation.

A fuel cell is an electrochemical energy conversion device that produces electricity from external supplies of fuel (on the anode side) and oxidant (on the cathode side). Generally, the reactants flow in and reaction products flow out while the electrolyte remains in the cell. Fuel cells can operate virtually continuously as long as the necessary fuel is maintained ${ }^{1-2}$. Additionally, while the electrodes within a conventional battery react and change as a battery is charged or discharged, but a fuel cell's electrodes are catalytic and relatively stable.

Hydrogen fuel cells have many advantages when compared with conventional energy sources. The power from a fuel cell is derived from hydrogen, an element that is extracted from many resources. The conversion of hydrogen to electricity using hydrogen fuel cell electrochemical conversion systems has no emissions; by products are water vapor and heat. Conventional energy production requires nonrenewable fuels and produces pollutants as well. Therefore hydrogen fuel is a viable energy source for the future in automotive, commercial, residential, portable, and many other electrical power applications.

Hydrogen fuel cell technology can response to almost all energy needs from home appliances to industrial machines by designing the fuel cell stacks according to the energy needs of the load. A fuel cell stack, composed of individual fuel cells wired in series similar to batteries, offers increased power output. Some fuel cell stacks containing thousands of individual cells are 
capable of generating the high voltages and currents needed for much transportation, commercial and industrial power applications ${ }^{3}$.

\section{Typical Working Principles}

As mentioned earlier a fuel cell is similar to a battery as it operates on the electrochemical energy conversion principle but there is an important difference; a fuel cell does not store fuel like a battery, but runs on a continuous supply of fuel. While efficiency of a heat engine is limited by the Carnot efficiency ${ }^{4}$, since a fuel cell works on an electrochemical principle, its efficiency is not limited by Carnot and thus can achieve a higher efficiency than a heat engine. Thus, a fuel cell achieves the continuous energy transformation from chemical to electrical form and high efficiency making it an excellent choice for power generation ${ }^{1}$.

The experimental hydrogen fuel cell system in this work investigates the conversion of potential energy stored chemically as hydrogen and oxygen gas to electrical energy using a protonexchange or Polymer Electrolyte Membrane (PEM) fuel cell. The PEM fuel cell is embedded with other energy conditioning electronics into EPAC-500 Hydrogen fuel cell system. A PEM fuel cell generates electricity by reacting hydrogen and oxygen gas together forming by products of vapor and heat. In this kind of fuel cell, hydrogen is split into protons at the anode, which in practice is a thin layer of catalyst on the surface of a polymer membrane. Then hydrogen ions move across the membrane to the cathode where they mix with oxygen and electrons that have moved to the cathode from the anode via an external electrical load circuit.

\section{Applications of Fuel Cells}

Fuel cells are very useful as power sources in remote locations, such as spacecrafts, remote weather stations, parks, rural locations, and in certain military applications. A fuel cell system running on hydrogen can be compact, lightweight and has no major moving parts. Because fuel cells have no moving parts, and do not involve combustion, in ideal conditions they can achieve up to $99.99 \%$ reliability ${ }^{5}$. This equates to less than one minute of down time in a six year period. Furthermore, fuel cell systems can be designed and developed to power cars, trains, cell phones, cities, etc. Especially solar, wind and biomass energy systems are capable of working with fuel cells and hydrogen production technologies. Fuel cells also promise a clean and efficient future for the transportation technology. As of February 2008, major automakers in the United States are now working on developing fuel cell vehicles including in service fuel cell vehicle fleets in Los Angeles, Washington DC, and New York State for the United Postal service (UPS) ${ }^{4}$.

Besides the intensive research efforts there are already practical examples of fuel cell powered vehicles running on the streets. For example, the first public hydrogen refueling station was opened in Reykjavík, Iceland in April 2003. This station serves three buses built by DaimlerChrysler that are in service in the public transport net of Reykjavík. The station produces the hydrogen it needs by itself, with an electrolyzing unit, and does not need refilling. Chrysler Corporation also developed vehicles which separated hydrogen from gasoline in the vehicle. The purpose was to reduce emissions without relying on a nonexistent hydrogen infrastructure and to avoid large storage tanks ${ }^{7}$. The British firm Intelligent Energy produced the first ever working hydrogen run motorcycle called the ENV in 2005 as described Emission Neutral Vehicle. The 
motorcycle is capable of holding enough fuel to operate for four hours, and to travel 100 miles in an urban area. The maximum speed of the motorcycle is declared as 50 miles per hour ${ }^{8}$. The Honda is also going to offer motorcycles using fuel cells as a fuel source ${ }^{9-10}$. Similarly Honda press release included the company's next generation hydrogen vehicle in $2008^{11}$.

\section{Measurement Challenges}

Fuel cell test systems make a variety of measurements that require signal conditioning before the raw signal can be digitized by the data acquisition system. An important feature for the testing of fuel cell stacks is isolation. Each individual cell may generate about $1 \mathrm{~V}$, and a group of cells may reach up to $10 \mathrm{~V}$ because in a PEM the membranes are stacked together to yield higher voltages. High-performance stacks have hundreds of cells that result in voltage measurements that require common-mode rejection of several hundred volts. Because of this, the tester must not only have many channels that are capable of reading 1 to $10 \mathrm{~V}$ per channel, but also maintain isolation of hundreds of volts between the first and last cell in the stack. Because fuel cell test systems also include channel counts that can range anywhere from 100 to 1000 channels, data acquisition system capable of expansion should be preferred for accuracy. These systems also have signals that require attenuation and amplification ${ }^{3}$. Modularity, ability to change with production and validation should be required for the test systems.

Based on the aforementioned criteria, it is obvious that simply monitoring the voltage is not sufficient to characterize and control a fuel cell system. Monitoring current output, temperature, and hydrogen consumption is also necessary. Because the current output can be very high, it is usually monitored by the Hall Effect property based transducers, where the current flowing is monitored through a wire. This method requires signal conditioning and scaling to convert the data back into a current reading. Another vital parameter for PEM fuel cells is temperature. To produce energy efficiently, PEM fuel cells must operate in the range of 60 to $80{ }^{\circ} \mathrm{C}$ (140 to 175 $\left.{ }^{\circ} \mathrm{F}\right)$. Temperature should be monitored to optimize variables such as variation and correlation to increase power output. Thermocouples and resistance temperature detectors (RTDs) are good sensors for monitoring both the stack temperature and the temperature of the incoming reactant gas streams. Moreover a mass flow meter to measure and control hydrogen flows between fuel cell stacks and the hydrogen tanks are required. This provides possibility of measuring amount of fuel that is consumed with a specific power load. Of course appropriate calculations have to be completed depending on the fuel source for accurate measurement. In this hydrogen fuel cell system, all the parameters that mentioned above are explained and measured using LabView ${ }^{\mathrm{TM}}$ PDS v8.20 software and field point based data acquisition modules.

\section{Fuel Cell Power Training}

The fuel cell power systems have specific power conditioning requirements to generate and supply reliable electricity. These requirements may depend on following load characteristics:

Regulation: The voltage from all sources of electrical power varies with time, temperature, pressure, and other factors and most importantly load current. Most electrical equipment works with a constant voltage with slight variation. A regulator using switching or chopping circuits is required to maintain a constant DC output voltage. 
DC to AC conversion: Our fuel cell provides low DC voltage. However, for stationary power generation, AC output is preferred. Hence a converter would be required to boost the DC voltage and an inverter to convert DC to AC voltage.

Battery backup: A fuel cell responds slowly to change in power demand. To meet the load fluctuations, a battery or a similar energy storage device is used.

The DC-AC conversion output from the fuel cell stacks forms the input to the DC-AC inverter, which produces an AC output voltage of 120/240V at 60/50 Hz. Figure 1 illustrates a functional block diagram of the hydrogen fuel cell system used in this work.

Pressure is measured with a pressure transducer and signal conditioning; hydrogen and airflow rates are typically measured with mass flow meters that generate pulses at a rate proportional to the gas flow rate. These pulses are then monitored by a counter board and scaled by software into a flow rate. Electronic regulators can control the pressure and flow via voltage or current outputs that are supplied by the test stand. The hydrogen mass flow rate measurement was not conducted for the system due to delays on broken mass flow meter sensor module replacement. Therefore there is no hydrogen pressure flow rate data is provided, during the time of this paper preparation. Unfortunately the time period between draft paper and full paper was not enough to conduct required tests to measure hydrogen efficiency by using Hydrogen mass flow meter. Since, MKS mass flow meter is not a NI product, it is very challenging to adapt this device to both NI LabView ${ }^{\mathrm{TM}}$ software and data acquisition modules. In order to preciously data reading from MKS mass flow meter it is very critical to comply interoperability between NI tools/software and mass flow meter. Otherwise wrong readings from the devices will affect data acquisition software calculations on NI LabView ${ }^{\mathrm{TM}}$ software that will eventually cause wrong reporting. Therefore, all results and related data based on mass flow meter measurements will be provided during the presentation of the paper at the conference.

\section{Student Tasks}

This instrumentation and data acquisition system has not been integrated to a class yet. Only few undergraduate and graduate students who have interest in energy systems and advanced instrumentation subjects have used the system for their senior projects and graduate work. Although this system has not been fully used in class in the program, the authors believe that it has a strong potential as an educational tool to explore the fuel cell technology in one system. A survey was given only to the students who used the system as part of their senior projects or graduate work. As recent survey information, one of the graduate students has been using the hydrogen fuel cell system for his research thesis is named "Development of Data Acquisition and Interface Module for a Fuel Cell Power Station." He has created his own NI LabView ${ }^{\text {TM }}$ interface and purchased different NI tools to improve the system. He learned and explored Hydrogen Fuel Cell system using the EPAC 500 power station. His comments are given as follows:

"I initially participated to write a scientific paper with one of the graduate students when the system was arrived to our department. We spent a lot of time to figure out the system and fixed some of the parts were initially came broken and unwired. At the time when fixing the system, I 
had a chance to learn how overall fuel cell systems work. I decided to select my graduate thesis subject on hydrogen fuel cell and their applications. I am sure that this system is very useful educational tool for the student projects and part of the sustainable energy classes. This system helps to explore overall fuel cell systems and would attract engineering students to make hands on experiments."

Students involved in this project conduct and demonstrate following tasks in order to achieve test results and prepare appropriate technical reports. This system is planned to be used and improved by the electrical engineering technology major students by adding more features and data acquisition interface at NI LabView ${ }^{\mathrm{TM}}$. These features included but not limited to measuring and controlling fuel pressure from hydrogen tanks, test variety of home appliances to measure efficiency and hydrogen consumption of the system, and possibly enhance the NI LabView ${ }^{\mathrm{TM}}$ user interface. Students should conduct the following steps described below to learn the overall design and implementation.

1. Check the appropriate safety rules and regulations of Hydrogen storage tanks and EPAC-500 Hydrogen fuel cell system.

2. Run the EPAC-500 Hydrogen fuel cell system for normal operation without any measurement and load connection to make sure system is operating appropriately.

3. Launch NI measurement automation explorer software to recognize NI field point data acquisition modules and establish communication between computer and compact field point. (Mostly NI based compact field point devices are used.)

4. LabView ${ }^{\mathrm{TM}}$ PDS V 8.20 is to be installed and configured for data acquisition and monitoring system variables such as hydrogen flow rate, temperature, pressure, and humidity of the hydrogen fuel cell, AC/DC voltage and current, power outputs, etc.

5. Develop a user friendly LabView ${ }^{\mathrm{TM}}$ control module interface.

6. Test overall system efficiency, and power output with a variety of electrical loads as case studies.

7. Investigate the possible and potential ways to reduce the hydrogen consumption and maintenance costs in order to compete with current market technologies including gasoline internal combustion engines.

8. For graduate students only, investigate external funding for a similar system with larger power capacity for research and education purposes to extend study of hydrogen fuel cell energy systems.

9. Publish a technical report of the test results and overall work to share with other institutions.

It is aimed that each step can be conducted by individual student or small group of students as a class project. Then all steps can be merged to test overall system efficiency by presenting each step with encountered issues and solutions. It can be part of the laboratory experiments to investigate variety of viable energy sources by performing experiments. The response of the students can be collected if they have positive or negative intentions. Students worked in the system stated that the use of "real" data makes the programming concepts taught in lecture much more meaningful to them. For many of these students, this experience involves the most intensive teamwork they have had to deal with in their educational experience. 


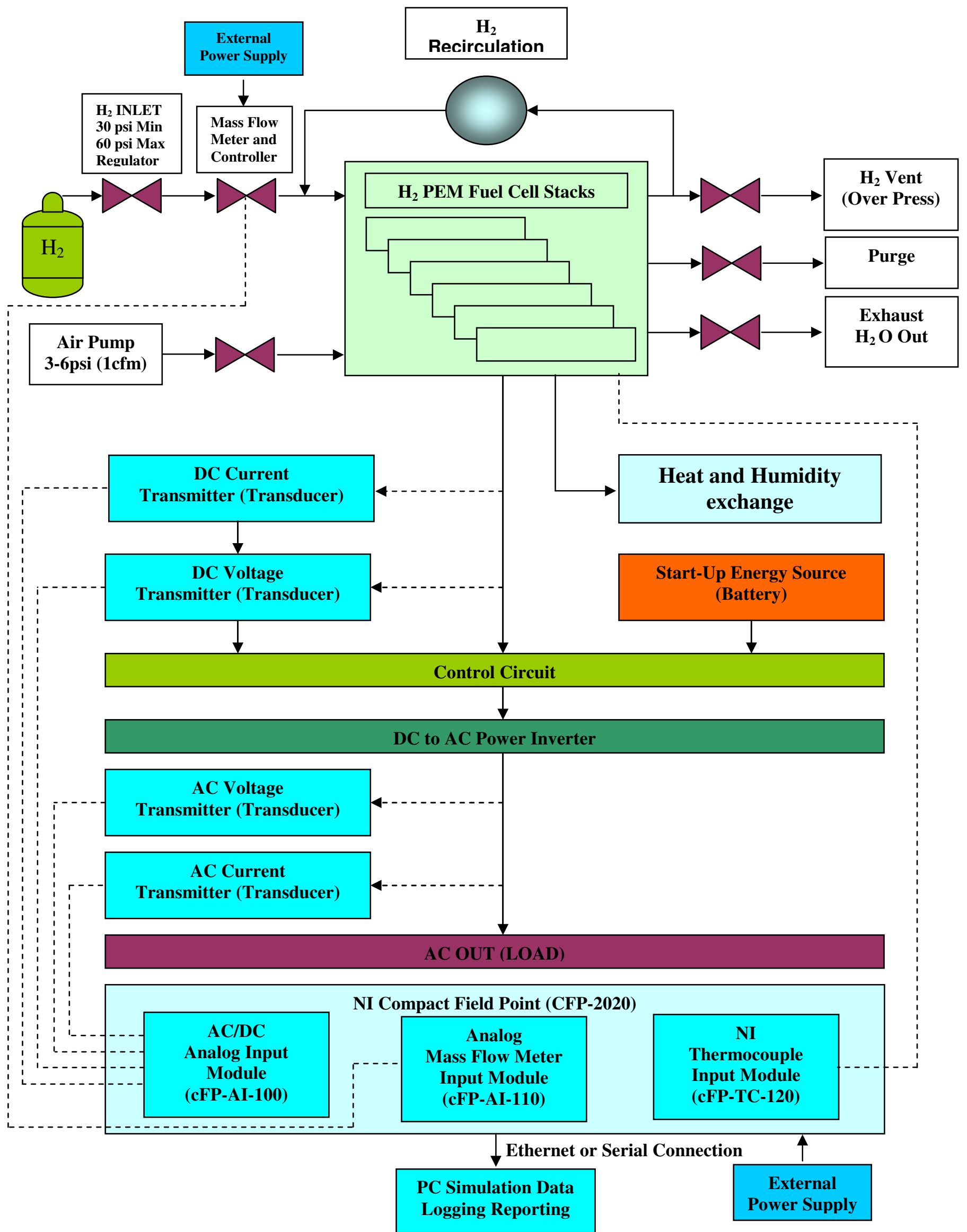




\section{EPAC-500 Hydrogen Fuel Cell Package}

The EPAC-500 Hydrogen fuel cell system is used to conduct hydrogen fuel cell to electricity conversion for the research purposes. The EPAC-500 is a self-contained, rack-mountable 500W fuel cell power source, designed for outdoor or indoor use and intended initially for industrial customers. The unit can be mounted in a standard 19" equipment rack and has 3 possible outputs - $120 \mathrm{VAC}$ at $60 \mathrm{~Hz}, 48 \mathrm{~V}$ regulated DC and $48 \mathrm{~V}$ unregulated DC. The system can be set to act as a stand-alone power source, or to self-start upon an electrical grid failure. In its initial form, the unit is designed to run on compressed hydrogen from standard industrial cylinders ${ }^{12}$. The picture of the EPAC-500 Hydrogen fuel cell system with the data acquisition tools and computer connections is shown in Figure 2.

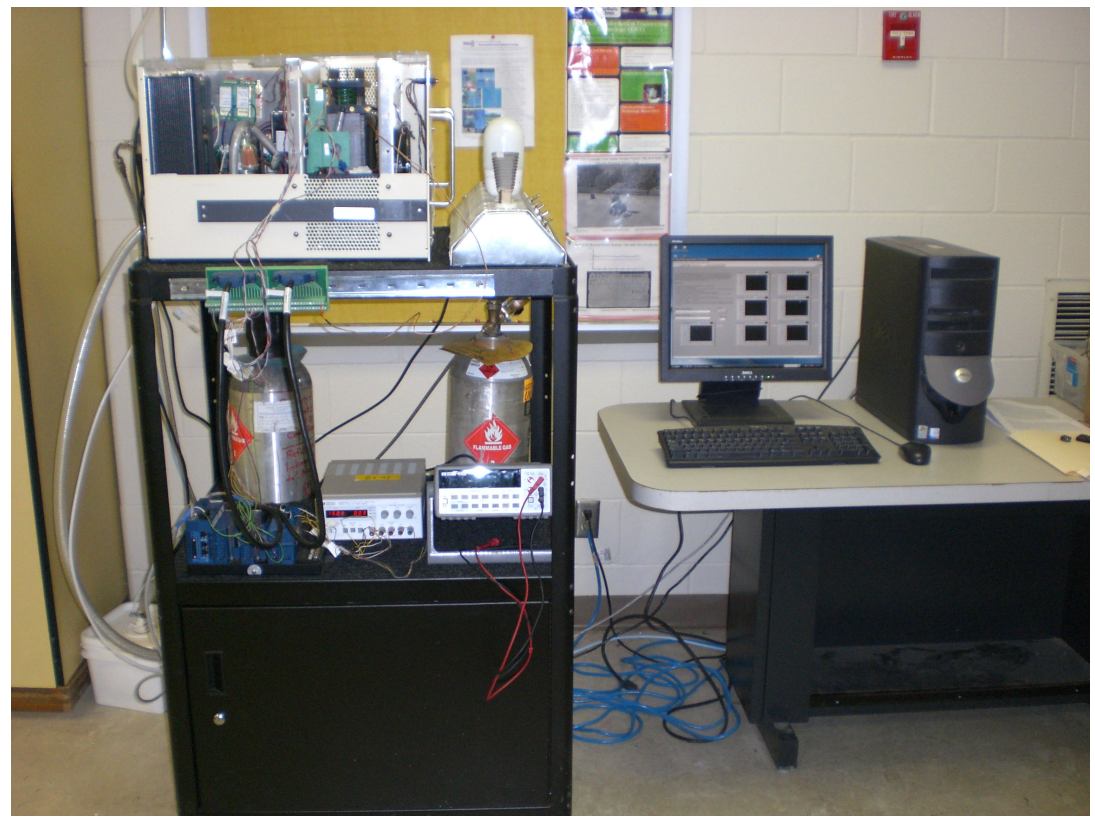

Figure 2: EPAC-500 Hydrogen Fuel Cell

\section{MKS 179A Mass-Flo® Type Mass Flow Meter}

Sudden changes in some parameters like temperature, pressure, hydrogen flow rate and variation in the load can cause the fuel cell to display irregular behaviors. For example a sudden increase in power demand causes the fuel cell voltage to drop harshly. The fuel cell system takes some time to supply the additional power and eventually the terminal voltage returns to the stable state value. The amount of fuel (hydrogen) supplied to a fuel cell determines the power generation capacity of the fuel cell. If the hydrogen supplied to the fuel cell is reduced then the fuel cell power output decreases, the polarization losses increase and the terminal voltage of the fuel cell decreases. The MKS Instruments 179A Mass-Flo ${ }^{\circledR}$ All-Metal Mass Flow Meter (MFM) is a mass flow meter (MFM) designed to measure the flow of gases in a wide variety of applications ${ }^{13}$. It is available in both analog and digital models with accuracy of $1 \%$ of full scale and $1 \%$ of reading, respectively. The power requirement for the device is kept minimal; the nominal \pm 15 VDC unit consumes only $50 \mathrm{~mA}$ during operation with only $150 \mathrm{~mA}$ at initial turn-on. Its standard 3 inch footprint enables to drop directly into the same space without modifying existing 
gas lines. Electrical connectors are the same PC edge card and is named type "D" connectors, with similar pin-outs, signals, and functions as their industry counterparts. The 179 is compatible with mass flow controller (MFC) power supply and display electronics from MKS or other manufacturers. This product is purchased and added to the current hydrogen fuel cell system to measure and control hydrogen fuel flow and consumption while load of the system is changed. The average hydrogen consumption rate will be reported according to the specific voltage and current loads.

\section{Hydrogen Flow Rate Calculations}

In order to calculate gas flow rate, Gas Correction Factor (GCF) is used to indicate the ratio of flow rates of different gases which will produce the same output voltage from a mass flow controller. The GCF is a function of specific heat, density, and the molecular structure of the gases. In our case pure hydrogen is used as the baseline gas but flow controllers are usually calibrated with nitrogen. To calculate the Gas Correction Factor (GCF) for pure gases, following formula is used:

$$
G C F_{x}=\frac{(0.3106)(S)}{\left(d_{x}\right)\left(c p_{x}\right)}
$$

where $\mathrm{GCF}_{\mathrm{x}}$ is the gas correction factor for gas $\mathrm{x}$ (In our case hydrogen gas used), 0.3106 is the factor of (Standard Density of nitrogen) and (Specific Heat of nitrogen), $\mathrm{S}$ is the molecular structure correction factor where $\mathrm{S}$ is 1.03 for monatomic gases, 1.0 for diatomic gases (Since $\mathrm{H}_{2}$ is diatomic gas 1.0 is selected as " $\mathrm{S}$ " factor), 0.941 for triatomic gases, and 0.880 for polyatomic gases, $\mathrm{d}_{\mathrm{x}}$ is the standard density of gas (Hydrogen), in $\mathrm{g} / 1$ (at $0^{\circ} \mathrm{C}$ and $760 \mathrm{~mm} \mathrm{Hg}$ ) and it is 0.0899 . The parameter $\mathrm{cp}_{\mathrm{x}}$ is the specific heat of gas (Hydrogen), in cal $/ \mathrm{g}^{\circ}$ $\mathrm{C}$ for Hydrogen and it is 3.419 .

$$
G C F_{x} \frac{(0.3106)(1)}{(0.0899)(3.419)}=1.01
$$

Our GCF function will be 1.01 to calculate hydrogen flow rate based on analog flow signal outputs between $0 \mathrm{~V}$ and +5 VDC. Using GFC function and flow signal outputs NI LabView ${ }^{\mathrm{TM}}$ interface and data acquisition field points will be configured to measure efficiency of the hydrogen fuel cell system on different loads.

\section{Software Platform for Data Acquisition}

The LabView ${ }^{\mathrm{TM}}$ data logging and supervisory control module from National Instruments meet the needs of fuel cell researchers with its built-in high-channel-count data acquisition, data logging, interface, and security capabilities. Fuel cell test systems may require hundreds of data acquisition sensors and controls for temperature, humidity, atmospheric pressure, oxygen, and other parameters. A typical test may include a parameter such as temperature to a certain point, holding it steady, and graphing the resulting voltage and current across the fuel cell. The LabView $^{\mathrm{TM}}$ data logging and supervisory control module includes an extensive historical database in which all measurement and test data acquired can be saved for later review and the user can load in test data and perform interactive offline analysis and report generation. Figure 3 depicts the interface of the NI LabView ${ }^{\mathrm{TM}}$ with no load while Figure 4 shows the NI field point measurement and automation explore software to collect readings from channels. As it is shown 
in Figure 3, hydrogen fuel cell system draws about 18.2 W DC power from the fuel cell stacks at no load condition. This power is needed by air filter motor, control circuit and inverter to keep the fuel cell system ready for the load conditions and sudden load changes.

\section{Hydrogen Fuel Cell Experiment as an Educational Tool}

This experiment investigates the conversion of potential energy, stored chemically as hydrogen and oxygen gas, to electrical energy using PEM fuel cell with the EPAC-500W system. The developed experiment also studies the relationship between voltage, current and power output for a PEM fuel cell, the effect that an electrical load (resistance) has on the average fuel cell voltage, current, power and hydrogen consumption rate, and the energy efficiency of the fuel cell.

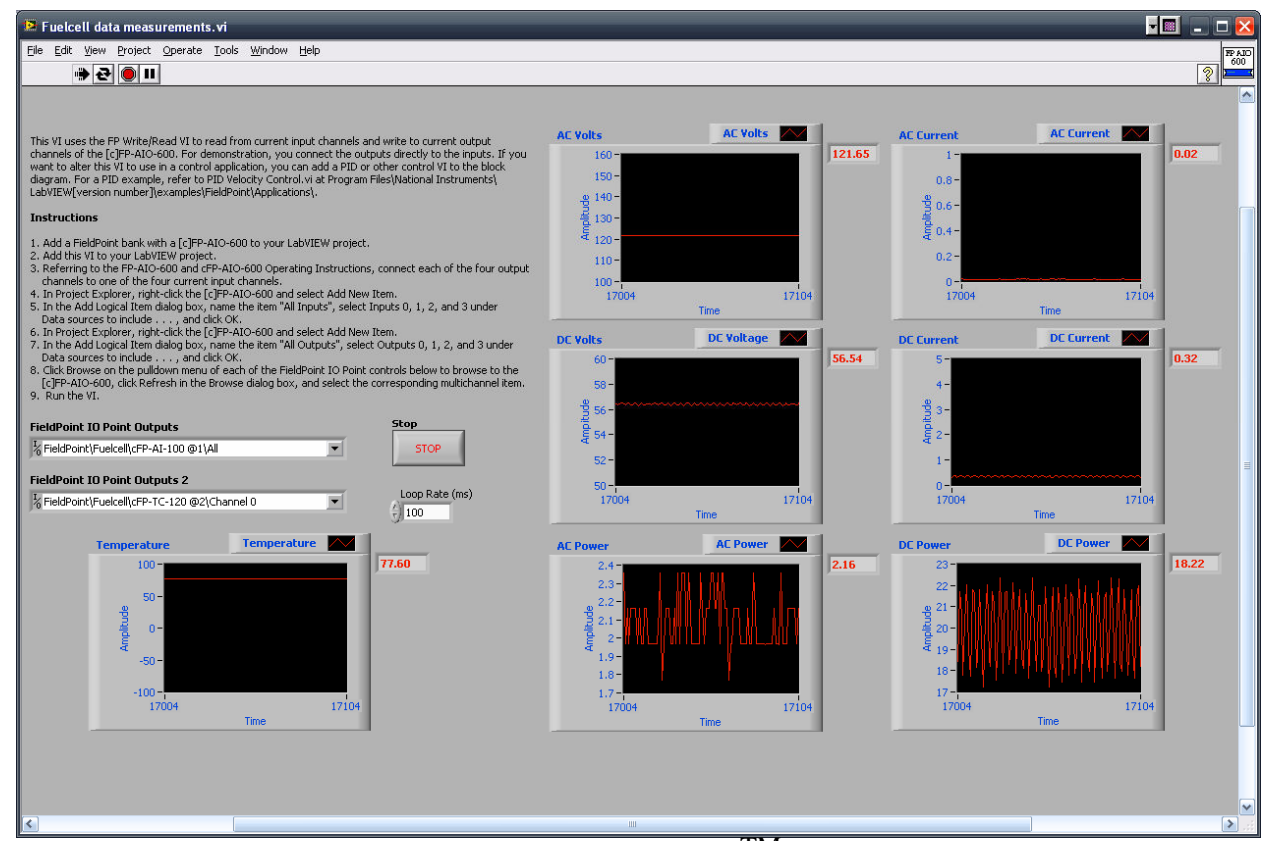

Figure 3: Screen shot of NI LabView ${ }^{\mathrm{TM}}$ interface with no load

A thermocouple was embedded in the fuel cell to monitor temperature as the reaction took place ${ }^{14}$. In this research NI computer-based measurement products are used for data acquisition and data logging purposes. These test tools have been essential in the production and testing of many types of fuel cells including PEM, phosphoric acid and solid oxide fuel cells.

\section{NI LabView ${ }^{\mathrm{TM}}$ Interface}

Since the system output is an AC output voltage of $120 \mathrm{~V}$ at $60 \mathrm{~Hz}$, overall system efficiency will be measured. The loads are incandescent and compact florescent light (CFL) bulbs, a blender as an $\mathrm{AC}$ electric motor, and electrical heaters controlled by switches. These switches allow us to add or reduce the load of the system. Thus, the efficiency of the system and hydrogen flow rate from the gas tank are measured with certain load changes. These changes will be stored in a data file to be compared for the future work and suggestions. 


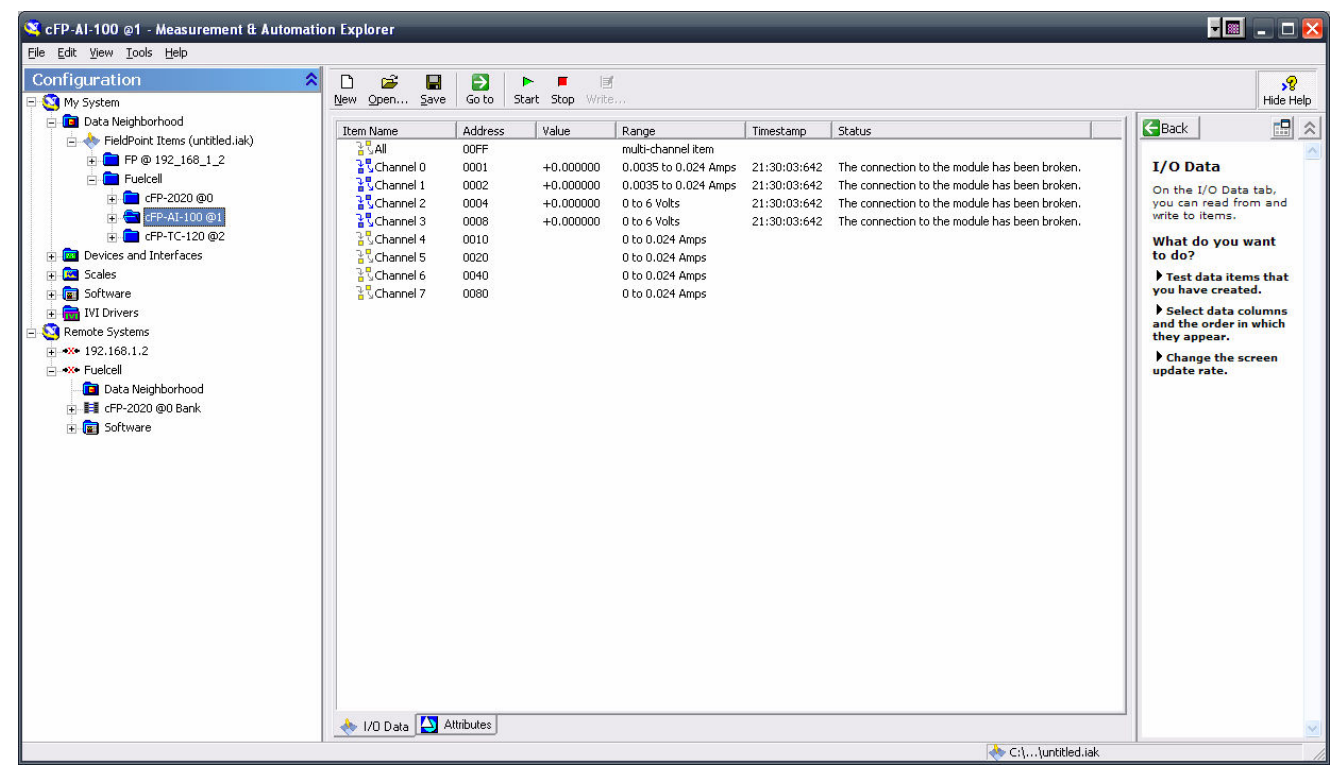

Figure 4: Screen shot of NI measurement \& automation software

The NI data acquisition modules are placed between computer and fuel cell system to convert analog input to digital output for the field point measurement. NI measurement and automation software recognizes channels of the data acquisition models such as voltage, current, temperature, and mass gas flow. The LabView ${ }^{\mathrm{TM}}$ field point block diagram interface is shown in Figure 5.

This Virtual Instrument (VI) uses the FP write/read VI to read from current input channels and write to current output channels of the module. For the actual connection, we connect the outputs directly to the inputs. If want to alter this VI to use in a control application, it can be added a PID or other control VI to the block diagram.

The following steps describe the data acquisition process:

1. Add a field point bank with a [c] FP-AI-100 to LabView ${ }^{\mathrm{TM}}$ project.

2. Add this VI to LabView ${ }^{\mathrm{TM}}$ project.

3. Referring to the [c] FP-AI-100 operating instructions, connect each of the four output channels to one of the four current input channels.

4. In project explorer, right-click the [c] FP-AI-100 and select add new item.

5. In the add logical item dialog box, name the item "All Inputs", select inputs $0,1,2$, and 3 under data sources to include necessary variables, and click OK.

6. In project explorer, right-click the [c] FP-AI-100 and select add new item.

7. In the add logical item dialog box, name the item "All Outputs", select outputs $0,1,2$, and 3 under data sources and click OK.

8. Click browse on the pull down menu of each of the FP I/O point controls below to browse to the [c] FP-AI-100, click refresh in the browse dialog box, and select the corresponding multi channel item and finally run the VI.

\section{Field Point Distributed Data Acquisition}

NI Field Point distributed I/O products are frequently used for fuel cell testing. Our system is consisted of NI Field Point tools include capabilities that improve the reliability and 
maintainability of the system. Since we deal very sensitive system and need accurate measurements NI local intelligence is very valuable for a fuel cell test platform because it provides onboard diagnostics and easy maintenance to maximize system uptime ${ }^{3}$. The module names and their types are indicated in Table I for the reference to similar applications.

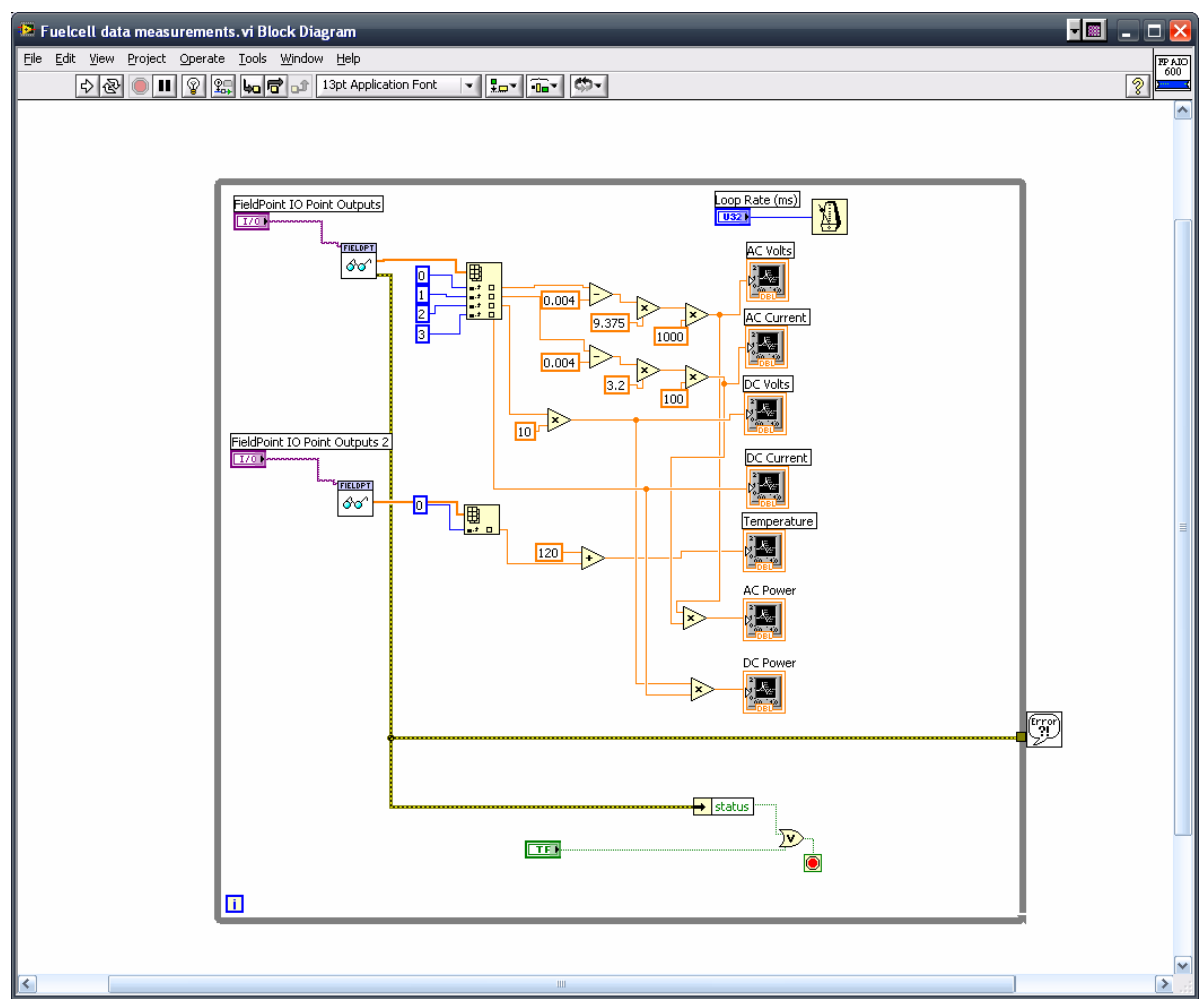

Figure 5: Lab VIEW data acquisition block diagram

Table I. Field Point-Based Test Platforms

\begin{tabular}{|l|l|l|l|}
\hline Measurement & Channel Type & Signal Conditioning & Field Point Modules \\
\hline Voltage & Analog Input & Isolation, Attenuation & cFP-AI-100 \\
\hline Current & Analog Input & Scaling, Attenuation & cFP-AI-100 \\
\hline Temperature & Analog Input & Scaling, Amplification & cFP-TC-120 \\
\hline Compact Field Point & Analog Input & Digital Output & cFP-2020 \\
\hline Hydrogen Flow Rate & Analog Input & Scaling, Attenuation & cFP-AI-112 \\
\hline
\end{tabular}

\section{Case Studies for Efficiency Analysis of Sudden Load Changes}

This case study includes inputs of sudden load changes considering a number of incandescent and florescent light bulbs, a blender run by an AC electric motor, and electrical heaters controlled by switches. These switches allow us to add or reduce the load of the system. Since the system output is AC output voltage of $120 \mathrm{~V}$ at $60 \mathrm{~Hz}$, AC system efficiency was measured and conducted. The loads are increased and reduced with switches from $0 \mathrm{~W}$ to $250 \mathrm{~W}$ to compare the efficiency. Thus, the efficiency of the system and hydrogen flow rate from the gas tank are measured with load changes. These changes were stored in data files to be compared for the 
future work and suggestions. The values derived from the tests results are arranged in Table II for the reference.

Table II. Case Study with different load changes

\begin{tabular}{|l|c|c|c|c|c|c|}
\hline & $\begin{array}{c}\text { Rated } \\
\text { Operation }\end{array}$ & $\begin{array}{c}\text { No } \\
\text { load }\end{array}$ & $\begin{array}{c}50 \mathrm{~W} \\
\text { load }\end{array}$ & $\begin{array}{c}100 \mathrm{~W} \\
\text { load }\end{array}$ & $\begin{array}{c}150 \mathrm{~W} \\
\text { load }\end{array}$ & $\begin{array}{c}200 \mathrm{~W} \\
\text { load }\end{array}$ \\
\hline DC Voltage Level [V] & & 56.54 & 53.61 & 52.21 & 50.18 & 50.62 \\
\hline DC Current Level [A] & & 0.32 & 1.37 & 2.44 & 2.57 & 4.68 \\
\hline AC Voltage Level [V] & & 121.65 & 121.7 & 121.84 & 121.7 & 121.94 \\
\hline AC Current Level [A] & & 0.02 & 0.44 & 0.87 & 1.27 & 1.71 \\
\hline System Temperature [F] & & 77.6 & 92.06 & 100.35 & 112.46 & 121.87 \\
\hline D.C. Power [W] & & 18.22 & 73.37 & 127.36 & 179.1 & 236.69 \\
\cline { 1 - 4 } A.C. Power [W] & & 2.16 & 53.24 & 105.42 & 154.04 & 208.05 \\
\cline { 1 - 4 } Losses & & 16.06 & 20.13 & 21.94 & 25.08 & 28.64 \\
\hline System efficiency [\%] & & TBA & TBA & TBA & TBA & TBA \\
\cline { 1 - 4 } & & & & & &
\end{tabular}

\section{Cost of the Overall System}

The cost of the system depends on the application and NI software/data acquisition tools. The EPAC 500 Fuel Cell Power Station and NI data acquisition modules were donated by National Instruments. The software tool NI LabView ${ }^{\mathrm{TM}}$ Version 8.20, additional NI data acquisition modules, MKS mass flow meter, and few connectors and cables were purchased. Besides, depends on hydrogen use, four hydrogen tanks are regularly refilled for the system operation. The time to set up the system including ordering additional software and hardware tools, rewiring, comply interoperability of the devices and software tools is about two and half months. The estimated cost of the parts is shown in Table III.

Table III: The estimated cost of the Hydrogen Fuel Cell System

\begin{tabular}{|l|l|l|}
\hline Part/Software & Unit & Price \\
\hline EPAC 500W Power Station & 1 & $\$ 14,000$ (donated) \\
\hline NI LabViewTM v 8.20 Developer Suite -Research & 1 & $\$ 2,400$ \\
\hline MKS 179A Mass-Flo® Mass Flow Meter & 1 & $\$ 920$ \\
\hline cFP-AI-100, Data Acquisition Module & 1 & $\$ 120$ (donated) \\
\hline cFP-TC-120, Data Acquisition Module & 1 & $\$ 140$ (donated) \\
\hline cFP-2020, Field Point & 1 & $\$ 240$ (donated) \\
\hline cFP-AI-112, Data Acquisition Module & 1 & $\$ 610$ \\
\hline Hydrogen Fuel Tanks & 4 & $\$ 360$ \\
\hline Dell Computer & 1 & $\$ 950$ \\
\hline Ethernet Networking cable & 1 & $\$ 25$ \\
\hline Field Point Connectors & 2 & $\$ 40$ (donated) \\
\hline Total & & $\$ 19,805$ (including donations) \\
\hline
\end{tabular}




\section{Conclusion and Recommendations}

Hydrogen fuel cells are important enabling technology for the hydrogen economy and have the potential to revolutionize a way to power our nation by offering cleaner, more efficient alternatives. Fuel cells have the potential to replace the internal combustion engine in vehicles and provide power in stationary and portable power applications. This system allows students to study the hydrogen fuel cell energy system from its primary source, characterize the efficiency of the overall process, and finally learn about applied data acquisition and instrumentation with its challenges.

The laboratory experiments were performed by teams of undergraduate/graduate students and an advisor for the establishment of the system. Ultimately, students who used the system are asked to consider how the hydrogen energy systems could be applied to develop real-world products that better serve the needs of humanity. Graduate students were required to evaluate their own, as well as their fellow students' performance and submit a written report. Students are gaining experience on using NI LabView ${ }^{\mathrm{TM}}$ computerized data acquisition systems applied on challenging energy issues. In the academic year of 2008-09, the fuel cell instrumentation system will be integrated into an undergraduate level computer aided instrumentation and interface class. Since the class is expected to have more than 15 students, a small group of laboratory sections will be considered at different time schedules according to student interest.

\section{References}

[1] R. Hinrichs, M. Kleinbach, "Energy Its Use and the Environment," $3^{\text {rd }}$ Edition, Harcourt College Publishers, 2002.

[2] R. A. Prabha, “An Advanced Fuel Cell Simulator”. Master of Science Thesis, B.E. College of Engineering, Texas A\&M University, 2004

[3] National Instruments "Fuel Cell Testing - The NI Way-Developer Zone”, Available online at http://zone.ni.com/devzone/cda/tut/p/id/2759, accessed December 2007.

[4] G. Hoogers, “Fuel Cell Technology Handbook”, Boca Raton, FL: CRC Press, 2003.

[5] The online Fuel Cell Information Resource, "Fuel Cell Basics and Benefits", Available online at http://www.fuelcells.org/basics/benefits.html, accessed January 2008.

[6] NEC Researchers Employ Carbon Nanotubes to Design Micro DMFC for Portables. October 2001, Available online at, http://www.hfcletter.com/letter/October01/feature.html, accessed January 2008

[7] Chrysler Fuel Cell Vehicles. Available online at http://www.allpar.com. Accessed January 2008.

[8] The ENV Bike. Intelligent Energy., http://www.envbike.com/

[9] Honda Develops Fuel Cell Scooter Equipped with Honda FC Stack, Honda Motor Co., August $24,2004$.

[10] Bryant, Eric (July 21, 2005). Honda to offer fuel-cell motorcycle. autoblog.com. Retrieved on 2007-05-27.

[11] Honda readies fuel-cell car for 2008 launch, CBC News, September 25, 2006. Retrieved on 2007-05-27.

[12] Hpower, "EPAC-500 specifications and features", available online at http://www.hpower.com, accessed May 2007

[13] 179A Mass-Flo® All-Metal Mass Flow Meter http://www.mksinst.com/product/Product.aspx?ProductID=64

[14] John E. Bean, James J. Carroll, John P. Dempsey, Andrew Strong, William R. Wilcox, “Adding a Hands-On Laboratory Experience to the Freshman Engineering Programming Class at Clarkson University", Clarkson University, 2006.

[15] National Action Plan for Energy Efficiency (2007). National Action Plan for Energy Efficiency Vision for 2025: Developing a Framework for Change. 